\title{
Performance Assessment of Tuning Methods for PID Controller Parameter used for Position Control of DC Motor
}

\author{
Husain Ahmed $^{1}$ and Dr. Abha Rajoriya ${ }^{2}$ \\ Research Scholar \\ ${ }^{1}$ Department of Electrical Engineering \\ Mewar University, Rajasthan, India \\ ${ }^{2}$ HOD Department of EE SISTEC Gandhinagar \\ Bhopal, M.P., India \\ husain_ahmed@rediffmail.com,abharajoriya@gmail.com
}

\begin{abstract}
In this paper, a comparison is made for tuning methods of PID controller to improve the performance of the position control system of DC motor. Firstly, the PID controller is tuned using conventional Ziegler -Nichols method and then by using Simulink Response Optimization tool box available in MATLAB software. Further, Fuzzy gain scheduling of PID controller is investigated in which fuzzy rules are utilized on-line to adapt the PID controller parameters based on the error and its first time derivative. The result shows that the gain scheduling scheme for DC motor position control system have presented superior performance compared to other methods.
\end{abstract}

Keywords: DC motor, Ziegler Nichols Method, Simulink Response Optimization Tool Box, MATLAB, and Fuzzy Gain Scheduling

\section{Introduction}

DC motors are important equipment in modern applications. They are widely used in robotics and in industries, because of their simple structure. In these applications, motor should be precisely controlled so as to give desired performance. The position control of DC motor under varying parameters and external disturbance is a challenging task. This problem is difficult to be solved by using conventional methods of parameter tuning [1]. Conventional controllers have poor performances due to the non-linear features of DC motors such as saturation and friction.

The PID controllers are mostly used for controlling the position of DC motor. The tuning of the PID controller parameters is usually done using Ziegler Nichols method [2]. This conventional method is observed to be a time consuming process. Therefore a search for fast and reliable tuning method is a necessity.

MATLAB software provided a tool known as Simulink Response Optimization tool box. This toolbox helps optimizing the tuning parameters using conventional optimization technique [3]. For tuning PID parameters in the presented work, this toolbox has been applied next for the comparison purpose. The results observed are fast but accuracy is limited in it.

Fuzzy logic is a powerful tool in controlling the system parameters. It is derived from fuzzy set theory introduced by Zadeh in 1965. In fuzzy set theory, the transition between membership and non-membership can be gradual. Therefore, boundaries of fuzzy sets can be vague and imprecise, making it useful for ill structured systems [4, 5]. Fuzzy Logic controller 
is a rule based system which can be used when mathematical model of systems are imprecise [6]. Fuzzy logic controllers can be used in two ways, first as a part of control loop and second as a supervisor. Supervisory features can be used in tuning the parameters of PID controller. This type of technique is known as fuzzy gain scheduling techniques [7-10]. As an intelligent technique, Fuzzy logic is applied next for position controlling of DC motor

In the presented work the second approach i.e., fuzzy gain scheduling is used for online parameter controlling. The performance of the designed fuzzy logic controller (FLC) and classic PID position controllers using Ziegler Nichols tuning for DC motor is compared and investigated for time specific performance. Finally, the result shows that the fuzzy logic approach has minimum overshoot, minimum transient and steady state parameters, which shows the more effectiveness and efficiency of FLC than conventional PID model to control the position of the motor.

The paper is organized as follows: Section 2 describes the DC motor model, Section 3 describes the structure of simple PID controller, Section 4 presents ZN tuning methods, Matlab Simulink optimization techniques of tuning, Section 5 covers FGS, Section 6 presents the results and discussion, and finally section 7 concludes this paper.

\section{DC Motor Model}

The motor considered in the presented work is a field controlled with fixed armature current type D C motor. The transfer function between the output angular displacement of this motor shaft $\theta(t)$ and its input control action $U(t)$ is given by [11]:

$$
\frac{\theta(s)}{U(S)}=\frac{K_{m}}{s\left(T_{f} S+1\right)\left(T_{m} S+1\right)}
$$

Where $K m$ is motor gain constant, $T_{f}$ is time constant of field circuit and $T_{m}$ is time constant of inertia-friction element. For simplicity, we assume that $K_{m}=1$ radian/volt-sec, $T_{f}=0.1 \mathrm{sec}$ and $T_{\mathrm{m}}=1 \mathrm{sec}$

\section{PID Controller Design}

Most common structure of PID controller which is used for controlling various processes in industries is applied in our work for position control of DC motor. The block diagram of the same is shown in Figure 1.

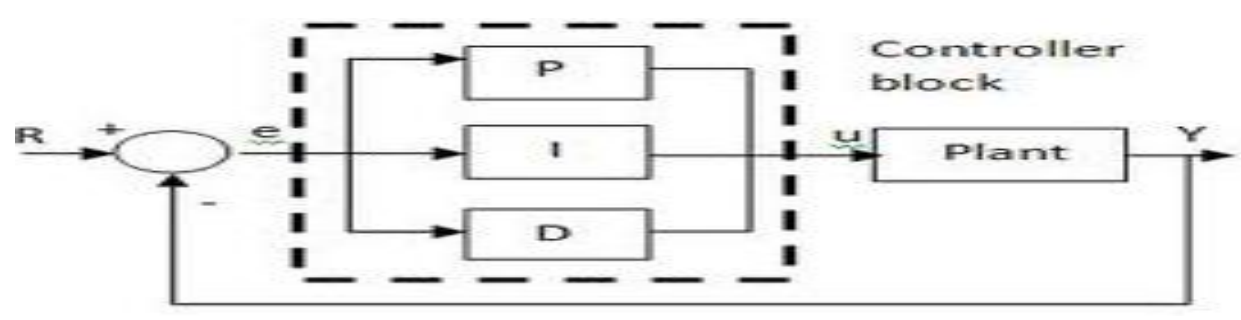

Figure 1. PID Control System

The control signal produced by the PID controller is a linear combination of error, its integral and derivative, given by following equations [11]. 


$$
\begin{aligned}
& u(t)=K_{p} e(t)+K_{i} \int_{0}^{t} e(\tau) d \tau+K_{d} \frac{d e(t)}{d t} \\
& u(t)=K_{p}\left(e(t)+\frac{1}{T_{i}} \int_{0}^{t} e(\tau) d \tau+T_{d} \frac{d e(t)}{d t}\right)
\end{aligned}
$$

Where, $K_{\mathrm{p}}$ is Proportional gain, $K_{\mathrm{i}}$ is Integral gain, $K_{d}$ is Derivative gain, $T_{\mathrm{i}}$ is Integral time constant, and $T_{d}$ is Derivative time constant. For a digital PID controller, the derivative term is replaced by difference and the integral term is replaced by a sum in the above equation. If the sampling time constant $\mathrm{T}$, is small, equation (2) can be approximated as

$$
u(m)=K_{p}\left(e(m)+\frac{1}{T_{i}} \sum_{i=1}^{m} e(i) T+T_{d} \frac{e(m)-e(m-1)}{T}\right) \cdots \cdots
$$

\section{Tuning PID Parameters}

\section{A. Using Ziegler- Nichols Method}

PID controllers are usually tuned using hand tuning or Ziegler- Nichols Method. Hand tuning generally done by experienced control engineers based on the rules shown in Table 1. It has to be taken into account that these rules are not always valid. For example if an integrator exists in the plant, then increasing $K_{p}$ results in more stable control.

Table 1. Effect of $K p, K i$ and $K d$

\begin{tabular}{|l|l|l|l|}
\hline Closed loop response & Overshoot (Mp) & Settling Time (ts) & Steady State Error (ess) \\
\hline Increasing Kp & Increase & Small Increase & Decrease \\
\hline Increasing Ki & Increase & Increase & Large Decrease \\
\hline Increasing Kd & Decrease & Decrease & Minor Change \\
\hline
\end{tabular}

The disadvantage of this method is that it requires a long time to find the optimal values. Another method used for tuning the parameter is Ziegler- Nichols frequency method. In this method $T_{i}=\infty$ and $T_{d}=0$ is set initially and then using the proportional action only, value of $K_{p}$ is increased from 0 to a critical value $P_{c r}$ at which the output exhibits sustained oscillations. Then the critical gain $P_{C r}$ and the corresponding period $T_{c r}$ are to be determined from graph. Ziegler-Nichols (Z-N) suggested that the value of, $K_{p}, T_{i \mathbb{i}}$ and $T_{\mathbb{d}}$ can be found out by using the formula shown in Table 2.

Table 2. PID Controller Parameters According to Ziegler-Nichols Method

\begin{tabular}{|l|l|l|l|}
\hline $\begin{array}{l}\text { Controlle } \\
\mathrm{r}\end{array}$ & $K_{\mathrm{p}}$ & $T_{\mathrm{i}}$ & $T_{\mathrm{d}}$ \\
\hline $\mathrm{P}$ & $0.5 P_{C r}$ & $\infty$ & 0 \\
\hline $\mathrm{PI}$ & $0.45 P_{C r}$ & $T_{c r} / 1.2$ & 0 \\
\hline $\mathrm{PID}$ & $0.6 P_{C r}$ & $0.5 T_{C r}$ & $0.125 T_{C r}$ \\
\hline
\end{tabular}

For the DC motor, the unit step responses for different values of gain $K_{p}$ were observed. Sustained oscillations were obtained for the value of $K_{p}=11$ (Figure 2). 


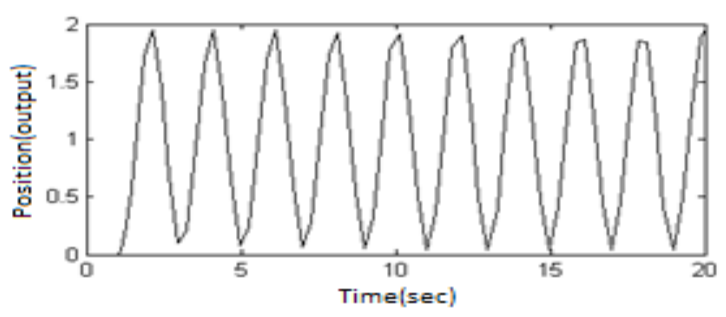

Figure 2. Time Versus Position Response for $K_{w}=11$

The above response clearly shows that sustained oscillation occurs for the value of $P_{C F}=11$. The corresponding time period $T_{c r}$ obtained from the time response is 2 . The value of controller parameters determined from these two values (with the help of Table 2) are $K_{p}=6.6, T_{i}=1, T_{d}=0.25$. The unit step response of the closed loop system with above values of controller parameters is shown in Figure 3 and performance specification of PID control system for DC motor with these obtained values is shown in Table 3.

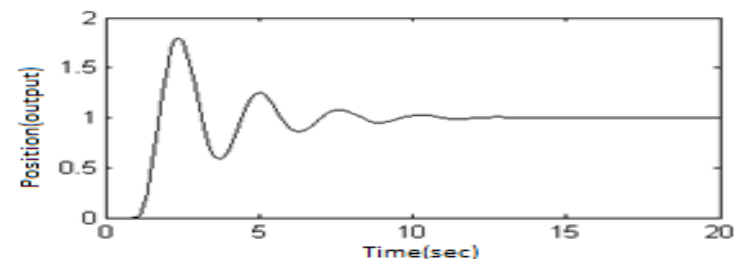

Figure 3. Unit Step Response for $K_{v}=6.6, T_{i}=1, T_{d}=0.25$

\section{Table 3. Performance Specifications for PID Control System using Ziegler Nichols Tuning}

\begin{tabular}{|l|l|l|l|}
\hline$t_{\mathrm{r}}$ & $t_{\mathrm{g}}$ & $M_{\mathrm{p}}$ & $\Theta_{\mathrm{gs}}$ \\
\hline $0.3 \mathrm{sec}$ & $12.5 \mathrm{sec}$ & $41 \%$ & $0 \%$ \\
\hline
\end{tabular}

As seen from the above results that the value of rise time $\left(t_{r}\right)$ and steady state error $\left(e_{s s}\right)$ are within desirable limits whereas overshoot $(M p)$ and settling time $\left(t_{g}\right)$ are too high. In position control this is an undesirable condition. So, with the initial values of, $K_{p}, T_{\mathfrak{i}}$ and $T_{d}$ obtained from Z-N formula, unit step response for different combination of $K_{p}, T_{\mathfrak{i}}$ and $T_{\mathbb{d}}$ were observed. Further, after fine tuning of parameters, the unit step response for, $K_{p}=6, K_{i}=0.1$ and $K_{d}=3$ is plotted which is shown in Figure 4. Performance specification of PID control system for these values after fine tuning is shown in Table 4.

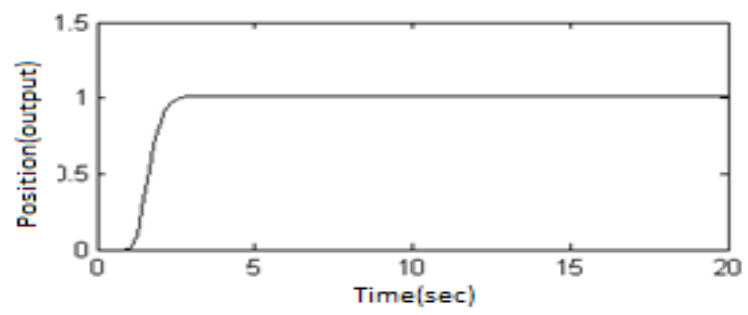

Figure 3. Unit Step Response for $K_{w}=6, K_{\mathrm{i}}=0.1, K_{d}=3$ 
Table 4. Performance Specifications for PID Control System after Fine Tuning of Ziegler Nichols

\begin{tabular}{|l|l|l|l|}
\hline$t_{F}$ & $t_{s}$ & $M_{p}$ & $\epsilon_{S G}$ \\
\hline $2 \mathrm{sec}$ & $1 \mathrm{sec}$ & $0 \%$ & $1 \%$ \\
\hline
\end{tabular}

As can be seen that both $M_{p}$ and $t_{s}$ are small as compared to the initial values obtained from Ziegler Nichols method. It concludes that with fine tuning, both peak overshoot and settling time can be reduced which is a favorable condition in position control of DC motor. Still the requirement for improvement in results is obvious for steady state error and rise time.

\section{B. Using Simulink Response Optimization Toolbox}

Another approach for optimization of the PID controller is available in Matlab Application software, known as Signal Constraint block of Simulink Response Optimization Toolbox. Signal Constraint is a block where response signals can be graphically constrained and model parameters should be automatically optimized to obtain the performance requirements [3]. Performance criteria specified for a unit step input is as follows;

Rise time $\leq 2.5 s$, Settling time $\leq 7.5 s$, Maximum overshoot $\leq 20 \%$, Steady state error $\leq 1 \%$. The objective in control system design is to find a control signal that satisfies the performance requirements [12]. Suppose that the following differential equation represent the mathematical model of the plant,

$$
\tilde{x}=f\left(x, u_{s} t\right) \ldots
$$

Where, $x$ - state variables vector and u-control vector. Also suppose that the controller is represented by,

$$
u=g\left(a_{v} h\right) x .
$$

Where, $a=\frac{a}{d t}$ differential operator, $g$-transfer matrix of the controller

Assume that transfer matrix structure is known and vector of controller parameters to be tuned $(h)$ also included in this structure. It is required to determine a reasonable set $\emptyset_{z}$ which represents the behavior of closed loop system at any time instant. It is obvious that this set should only be obtained by the choice of vector. Then the objective is to find an, $h$ vector that satisfies the performance requirements.

$$
x\left(h_{s} t\right) \in \emptyset_{x}, \forall t
$$

\section{Simulink Implementation}

Figure 5 shows the PID control system designed in MATLAB Simulink where controller coefficients were adjusted using the Signal Constraint Block.

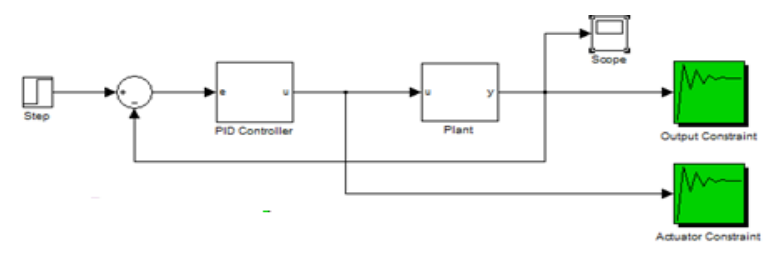

Figure 5. Simulink Implementation of PID Control System

Simulink response optimization toolbox helps in obtaining the optimal outputs for the involved system. Figure 6 shows the optimization process of controller parameters as 
obtained from the toolbox. The final values of parameters were obtained are $K_{\mathrm{p}}=1.5992, K_{\mathrm{i}}=-$ 0.0623 and $K_{d}=0.2311$.

It can be seen from Figure 6(a) that Signal Constraint block adjusted the parameters such that a very small overshoot occurs. Figure 6(b) shows the optimization progress for each iteration and found an optimal solution within the specified tolerances. Table 5 shows the values of the performance criteria obtained with the adjusted controller parameters. Steady state error and peak overshoot have been reduced to zero, settling time and rise time have also been reduced here. For further reduction in rise and settling time however Fuzzy Gain Scheduling technique has been explored.

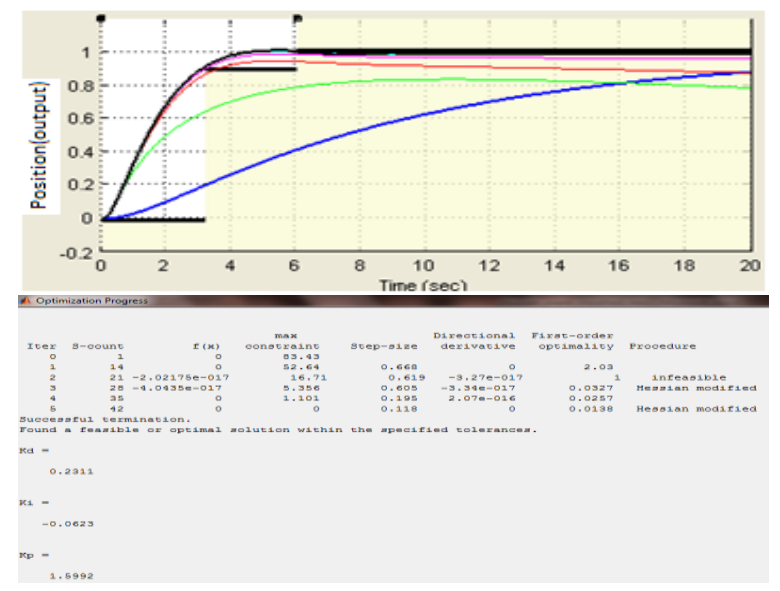

\section{Figure 6. (a) Optimization of PID Parameters (b) Optimization Progress}

\section{Fuzzy Gain Scheduling (FGS)}

Gain scheduling is a technique where PID controller parameters (gains) are tuned during control process, using the fuzzy rule base system. It is not always counted as an adaptive control, but it enlarges the operation area of a PID controller to perform well also for a nonlinear plant with unpredictable parameter variations [13].

In the proposed work, a fuzzy supervisor with two inputs-three outputs is used to schedule the controller parameters according to predefined parameter values with respect to changing operation conditions. The input variables are error and change in error and the outputs are $K_{p 1}$ $K_{\text {i1 }} K_{d 1}$. The overall scheme is shown in Figure 7.

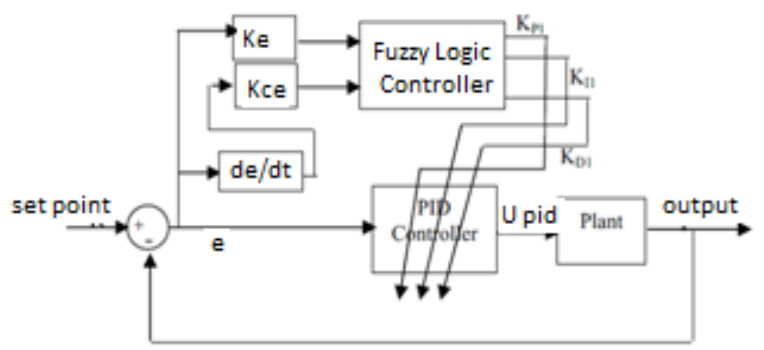

Figure 7. PID Control System with Fuzzy Gain Scheduling 
The PID parameters are tuned by using fuzzy inference, which provide a nonlinear mapping from the error and derivative of error to PID parameters.

The fuzzy logic control has four basic components [14]:

I. Fuzzification: This converts input data into suitable linguistic values. As shown in Figure 7, there are two inputs to the controller: error and rate change of the error signals. The error is defined as:

$$
e(t)=r(t)-y(t)
$$

Change in error is defined as it follows:

$$
\Delta e(t)=e(t)-e(t-1)
$$

Where $r(t)$ is the reference input, $y(t)$ is the output, $\Theta(t)$ is the error signal, and $\Delta e(t)$ is the rate of error. The five input trapezoidal and triangular and four output triangular membership functions of the fuzzy self-tuning are shown in Figures (8) and (9). For the system under study the universe of discourse for both $e(t)$ and $\Delta e(t)$ are normalized in the range [-1,1], and the linguistic labels are Negative High(NH),Negative Low(NL), Zero(ZO), Positive Low(PL), Positive High(PH), and linguistic variables for $K_{p 1} K_{i 1}$ and $K_{d 1}$ are Zero(ZO), Low(L), $\operatorname{Medium}(\mathrm{M}), \operatorname{High}(\mathrm{H})$ and normalized in the range[0,1].

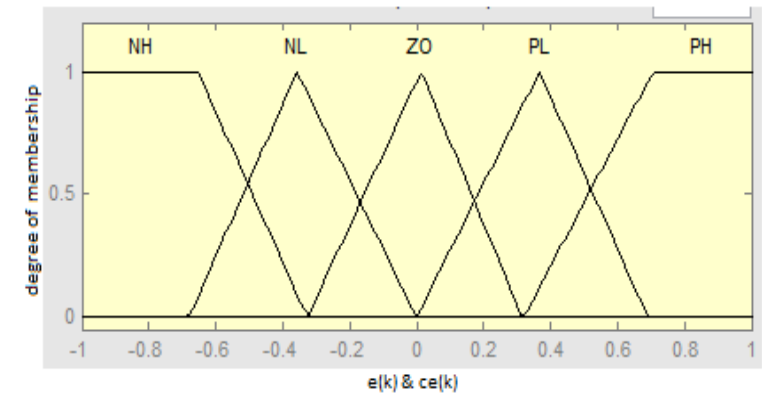

Figure 8. Membership Function for $\theta(k)$ and $C e(k)$

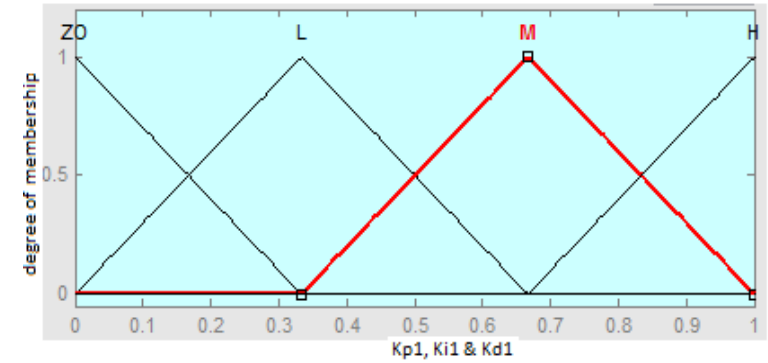

Figure 9. Membership functions for $K_{\mathrm{p} 1} K_{\mathrm{i1}}$ and $K_{\text {d1 }}$

II. Rule Base: Fuzzy PID controllers are knowledge based systems, so rules are formed based on what type of time response is desired from the system. These rules are framed based on experience of operator [15]. The parameters $K_{p 1} K_{i 1}$ and $K_{d 1}$ for proposed controller are determined by a set of fuzzy rules as:

If $e(k)$ is $A j$ and $c e(k)$ is $B j$ then $K_{p 1}$ is $C_{j}, K_{i 1}$ is $D_{j}$ and $K_{d 1}$ is $E_{f} j=1,2,3, \ldots . ., m$ and $m$, is the number of rules.

Here, $A_{j} B_{j} C_{\tilde{f}} D_{j}$ and $E_{j}$ are fuzzy sets of the corresponding sets. The membership functions for these variables are shown in Figures (8) and (9). 
The gains $K_{\mathrm{p} 1} K_{\mathrm{i} 1}$ and $K_{\mathrm{d} 1}$ of PID controller are so chosen to achieve a fast rising time, smaller overshoot and no steady state error for the system.

Figure 10 represents the desired time response. The time response is divided in three parts: below set point, the error is positive and above set point the error is negative and around set point error is nearly zero. In accordance with this response, the rules must be written. Initially, i.e., around $\mathrm{a}_{1}$, when error is positive, a big control signal is required to achieve a fast rise time. For big control signal, the PID controller should have a large proportional gain, a large integral gain and derivative gain is zero.

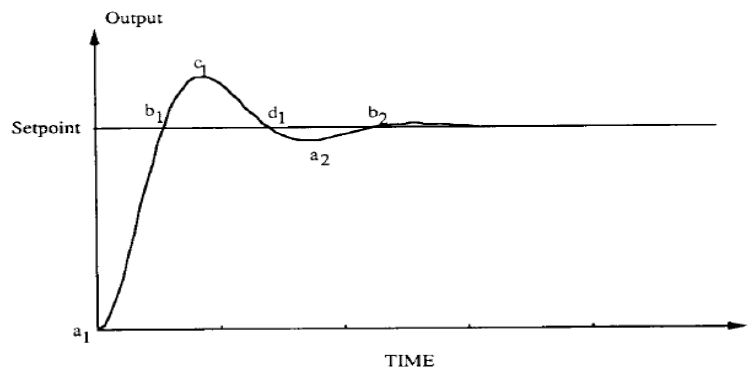

Figure 10. Unit Step Response for Controlled System

Therefore rule around $\mathrm{a}_{1}$ written as follows:

If $e(k)$ is $P H$ and $c e(k)$ is ZO then $K_{p 1}$ is $H, K_{i 1}$ is $H$ and $K_{d 1}$ is $Z O$

Now, around $b_{1}$, when error is nearly zero, a small control signal is needed, otherwise a large over shoot occurs i.e., $K_{\mathrm{p} 1}$ is small, $K_{\mathrm{i} 1}$ is small and $K_{d 1}$ should be large. So, the rule for this case is as follows:

If $e(k)$ is zo and ce(k) is $N H$ then $K_{p 1}$ is $L, K_{i 1}$ is $L$ and $K_{d 1}$ is $H$

By following the same procedure, the others rules can be written, which is summarized in Table (5, 6 and 7$)$.

Table 5. Tuning Rule for $K_{\mathrm{v}}$

\begin{tabular}{|c|c|c|c|c|c|}
\hline Cele & NH & NL & ZO & PL & PH \\
\hline NH & H & M & ZO & L & L \\
\hline NL & H & M & ZO & L & H \\
\hline ZO & H & H & H & H & H \\
\hline PL & H & H & L & M & H \\
\hline PH & H & M & L & M & ZO \\
\hline
\end{tabular}

Table 6. Tuning Rule for $K_{i}$

\begin{tabular}{|c|c|c|c|c|c|}
\hline$C e / e$ & $\mathrm{NH}$ & $\mathrm{NL}$ & $\mathrm{ZO}$ & $\mathrm{PL}$ & $\mathrm{PH}$ \\
\hline NH & $\mathrm{L}$ & $\mathrm{H}$ & $\mathrm{H}$ & $\mathrm{M}$ & $\mathrm{L}$ \\
\hline NL & $\mathrm{L}$ & $\mathrm{M}$ & $\mathrm{H}$ & $\mathrm{M}$ & $\mathrm{L}$ \\
\hline ZO & $\mathrm{L}$ & $\mathrm{L}$ & $\mathrm{M}$ & $\mathrm{L}$ & $\mathrm{ZO}$ \\
\hline PL & $\mathrm{L}$ & $\mathrm{M}$ & $\mathrm{M}$ & $\mathrm{M}$ & $\mathrm{L}$ \\
\hline PH & $\mathrm{L}$ & $\mathrm{H}$ & $\mathrm{H}$ & $\mathrm{M}$ & $\mathrm{B}$ \\
\hline
\end{tabular}


Table 7. Tuning Rule for $K_{a}$

\begin{tabular}{|c|c|c|c|c|c|}
\hline Cele & NH & NL & ZO & PL & PH \\
\hline NH & ZO & H & H & H & L \\
\hline NL & ZO & H & H & M & M \\
\hline ZO & L & L & H & L & H \\
\hline PL & L & H & H & M & M \\
\hline PH & L & H & H & H & L \\
\hline
\end{tabular}

III. Defuzzification: Finally the defuzzification process converts the fuzzy output into crisp control signal [16]. The mostly used defuzzification method is 'center of gravity' or 'center of area':

$$
u(n T)=\frac{\sum_{j=1}^{w} w\left(u_{j}\right) u_{f}}{\sum_{j=1}^{m} w\left(u_{j}\right)}
$$

Where $u\left(u_{j}\right)$ member ship grade of the element $u_{j}, u(n T)$ is the fuzzy control output, $n$ is the number of discrete values on the universe of discourse.

\section{Results and Discussion}

The actual scheme applied in the proposed work to a DC motor whose transfer function is derived from equation (1), is shown in Figure 11.

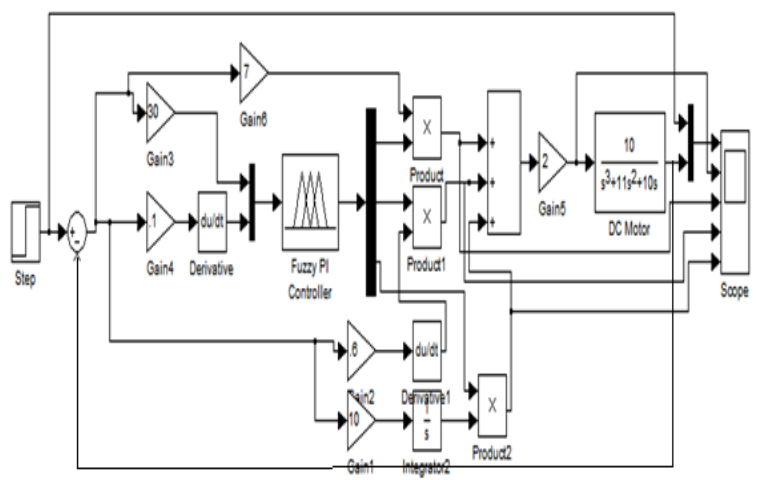

\section{Figure 11. Simulink Block Diagram of Gain Scheduling Scheme}

The results were obtained using ZN-PID controllers, fine-tuned PID controllers and MATLAB/SIMULINK based tuning are also presented for comparison, with fuzzy gain scheduling of PID controller, as shown in Figure 12. The results shows that the FGS using fuzzy logic control achieve better performance for tuning the PID gains than conventional tuning methods such as eliminating overshoot, rise time and steady state error.

Table 9. Performance Specifications for PID Control System using Fuzzy Gain Scheduling Scheme

\begin{tabular}{|l|l|l|l|}
\hline$t_{y}$ & $t_{s}$ & $M_{p}$ & $e_{s g}$ \\
\hline $0.8 \mathrm{sec}$ & $0.3 \mathrm{sec}$ & $0 \%$ & $0 \%$ \\
\hline
\end{tabular}




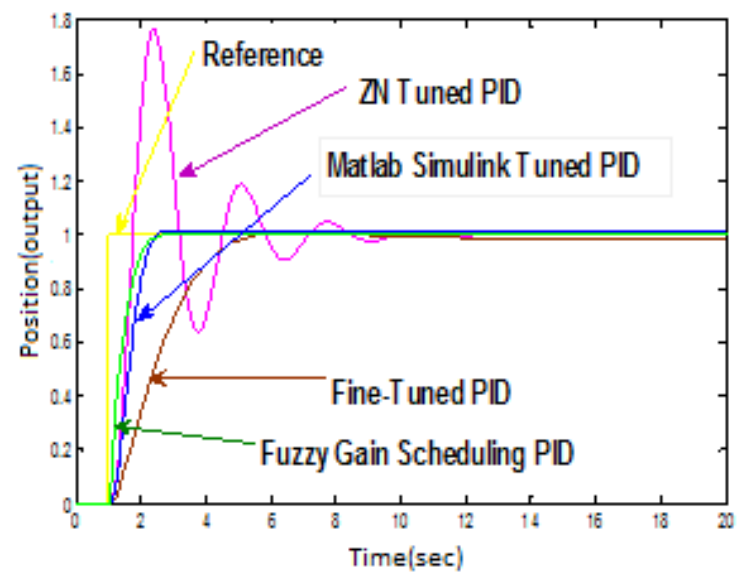

\section{Figure 12. Comparative Position Output Response Using Different Tuning Methods}

\section{Conclusion}

DC motor position control is an important area of research due to wide application of DC motor in industries and in robotics. Conventional method of position control of DC motor such as Ziegler-Nichole method with hand tuning is a cumbersome method. Moreover it is not providing accurate position control. For the accurate position control of the motor, an intelligent approach has been presented here. The approach provides Fuzzy gain scheduling based PID Controller, using Mamdani's method. The proposed approach has been compared with conventional Ziegler -Nichole method output and with Simulink based optimization toolbox output. It has been found that the fuzzy gain scheduling based PID controller as modeled in MATLAB/SIMULINK is giving efficient position control as compared to both conventional method and Simulink based optimization method.

\section{References}

[1] C. C. Hang, K. J. Astrom and W. K. Ho, "Refinements of the Ziegler-Nichols Tuning Formula", IEEE Control Theory and Applications, vol. 138, no. 2, (1991) March, pp. 111-118.

[2] K. H. Ang, G. C. Y. Chong and Y. Li, "PID Control System Analysis, Design, and Technology", IEEE Transactions on Control Systems Technology, vol. 13, no. 4, (2005) July, pp 559-576.

[3] www.mathworks.com/R2009b (version7.9).

[4] E. H. Mamdani, "Applications of fuzzy logic to approximate reasoning using linguistic synthesis," IEEE Trans. on Computers, vol. 26, no. 12, (1997) December, pp. 1182-1191.

[5] M. K. Mishra, A. G. Kothari, D. P. Kothari and A. Ghosh, "Development of a Fuzzy Logic Controller for Servo Systems", IEEE Region 10 International Conference on Global Connectivity in Energy, Computer, Communication and Control (TENCON '98), (1998), pp. 204-207.

[6] H. Ahmed, A. Goel, A. Uniyal, A. Bahuguna and R. S. Patwal, "Performance Comparison of PID and Fuzzy Logic Controller Using Different Defuzzification Techniques for Positioning Control of DC Motors" Journal of Information Systems and Communication, ISSN: 0976-8742 \& E-ISSN: 0976-8750, volume 3, Issue 1, (2012), pp. 235-238.

[7] L. Wang, M. Tian and Y. Gao, "Fuzzy Self-adapting PID Control of PMSM Servo System," IEEE International Electric Machines \& Drives Conference, vol. 1, (2007) May, pp. 860-863.

[8] Z.-Y. Zhao, M. Tomizuka and S. Isaka, "Fuzzy gain-scheduling of PID controllers," IEEE Trans. Syst., Man Cybern., vol. 23, (1993), pp. 1392-1398.

[9] A. Visioli, "Tuning of PID Controllers with Fuzzy Logic," IEEE Control Theory and Applications, vol. 148, no. 1, (2001), pp. 1-8.

[10] R. P. Copeland and K. S. Rattan, “A Fuzzy Logic Supervisor for PID Control of Unknown Systems”, IEEE International Symposium on Intelligent Control, (1994) August, pp. 22-26.

[11] K. Ogata, "Modern Control Engineering”, Second Edition, Prentice-Hall, Inc., (1995). 
[12] E. I. Veremey and S. B. Pogojev, "Nonlinear Control Design Blockset", [Online] Available: http://matlab.exponenta.ru/nonlinecondes/book1/preface.php.

[13] M. Dotoli, B. Maione and B. Turchiano, "Fuzzy-Supervised PID Control: Experimental Results," the 1st European Symposium on Intelligent Technologies, (2001), pp. 31-35.

[14] G. Feng, "A Survey on Analysis and Design of Model-Based Fuzzy Control Systems," IEEE Trans. on Fuzzy Sys, vol. 14, no. 5, (2006) October, pp. 676-697.

[15] C. C. Lee, "Fuzzy Logic in Control Systems: Fuzzy Logic Controller-Part I", IEEE Transactions on Systems, Man and Cybernetics, vol. 20, no. 2, (1990) March/April, pp. 404-418.

[16] L. A. Zadeh, "Fuzzy sets," Information Control, vol. 8, (1965), pp. 338-353.

\section{Authors}

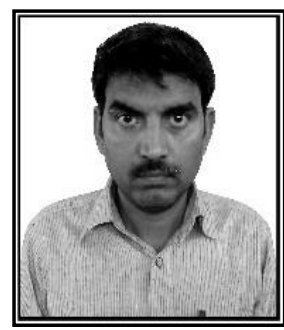

Husain Ahmed, he was born on $28^{\text {th }}$ March 1974 at Deoband (INDIA). $\mathrm{He}$ has obtained his B.E. in Electrical engineering \& M. Tech. In Instrumentation \& control from Aligarh Muslim University, Aligarh, India. He is pursuing his Ph.D. from Mewar University, Rajasthan, India. $\mathrm{He}$ is currently worked as an Assistant Prof. in DIT University, Dehradun, Uttrakhand, India.

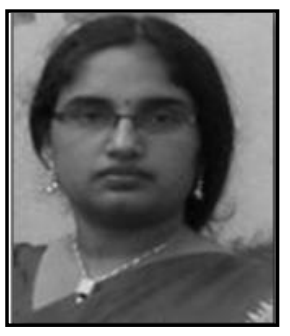

Dr Abha Rajoriya, she received Ph.D. degrees in electrical engineering from the Indian Institute of Technology, Roorkee, India in 2012. Currently she head of department of electrical \& electronics engineering of SISTEC, Ghandhinagar, Bhopal, M.P., India. Her research interest includes power system, fuzzy control system. 
International Journal of u-and e-Service, Science and Technology Vol.7, No.5 (2014) 